\title{
Heat Affected Zone in Welded Metallic Materials
}

\author{
Zakaria Boumerzoug* \\ Mechanical Engineering Department, University of Biskra, Algeria
}

*Corresponding author: Zakaria Boumerzoug, Mechanical Engineering

Department, LMSM, University of Biskra, Algeria.

Received Date: October 16, 2020

Published Date: November 04, 2020

\begin{abstract}
Welding is used extensively for pipe welding, aerospace, aviation, biomedical implants, fabrication of race cars, choppers, etc. Generally, the metallurgy of the welded joint performed by thermal fusion joining process can be categorized into two major regions, the fusion zone (FZ) and the heat-affected zone (HAZ). The heat-affected zone (HAZ) is a region that is thermally affected by the welding treatment. The main difficulty associated with welding is the prevention of unexpected deterioration of properties as a result of the microstructure evolutions which reduce the resistance to brittle fracture in the heat-affected zone (HAZ). Properties of the HAZ are different from those of the base material. According to the literature, the HAZ is the most problematic area in the high strength steels weld. For this reason, many research works investigated this critical zone in welded joint. The main research questions and results related to the HAZ will be presented.
\end{abstract}

Keywords: Welding; Heat affected zone; Microstructure; Mechanical properties; Thermal cycle simulation

Abbreviations: HAZ: Heat Affected Zone; Hv: Hardness Vickers; FZ: Fusion Zone; BM: Base Metal; T-HAZ: True Heat Affected Zone; PMZ: Partially Melted Zone

\section{Introduction}

Welding is a process of joining materials into unique piece. Welding is an enabling technology applied across almost all industries, from micro-joining of medical devices, electronics and photonics, to larger scale applications such as bridges, buildings, ships, rail, road transport, pressure equipment and pipelines [1]. Welding processes are divided into thermal fusion joining processes and solid-state joining processes. The most common processes of welding are thermal fusion joining processes such electric arc welding. This welding method is performed under high temperature conditions.

Heat generated during welding induces an important temperature gradient in and around the welded area. Generally, the metallurgy of the welded joint can be divided into two main zones, the fusion zone (FZ) and the heat-affected zone (HAZ). The HAZ is a zone which is outside the FZ of the welded joint that is thermally affected by the welding treatment. The HAZ is considered as a transition zone, because it is composed with the microstructure of the BM and the FZ. The properties of the HAZ are very important after performing a weld, because it is considered as a weaker zone, i.e.; the area of failure when the welded metal is submitted to hard conditions. For this reason, it is important to understand this critical zone in welded joint.

\section{Microstructures of HAZ}

The HAZ is the unavoidably heat treated area in the parent metal near the fusion zone during welding where structural transformations occur [2]. HAZ formed during welding is an area in 
which some structural changes in the welded material take place as the result of experienced temperature [3]. Figure 1 shows how the HAZ in welded XC38 steel differs significantly from the base metal. There was a development of a recrystallization reaction in HAZ, with the partial dissolution of the colonies of pearlite (dark color).

Depending on the distance from the weld, the different parts of the HAZ can be affected differently during the welding process There are many descriptions of the HAZ, because it can be divided in different subzones and each subzone has its own microstructure. For example, It has been considered that the HAZ can be divided into four different zones [2], as shown in Figure 2, which are subjected to different heat treatments:
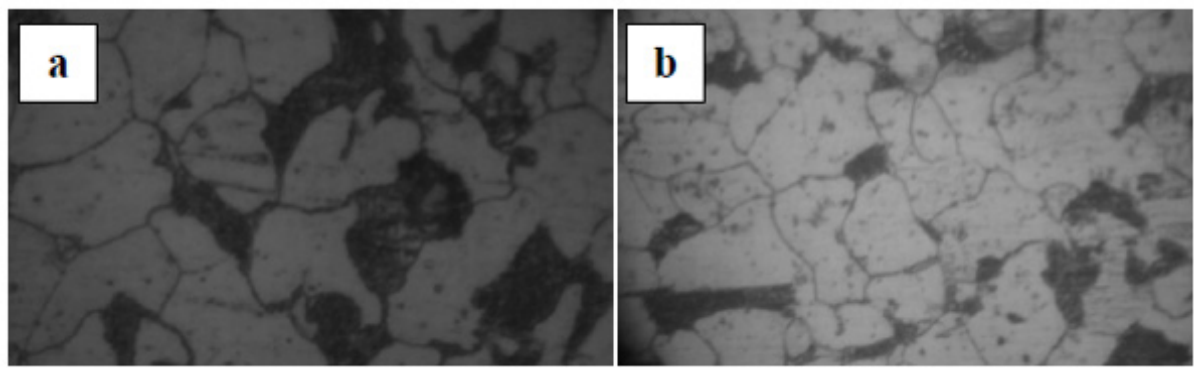

Figure 1: Microstructure of (a) base metal and (b) HAZ of welded XC38 steel.

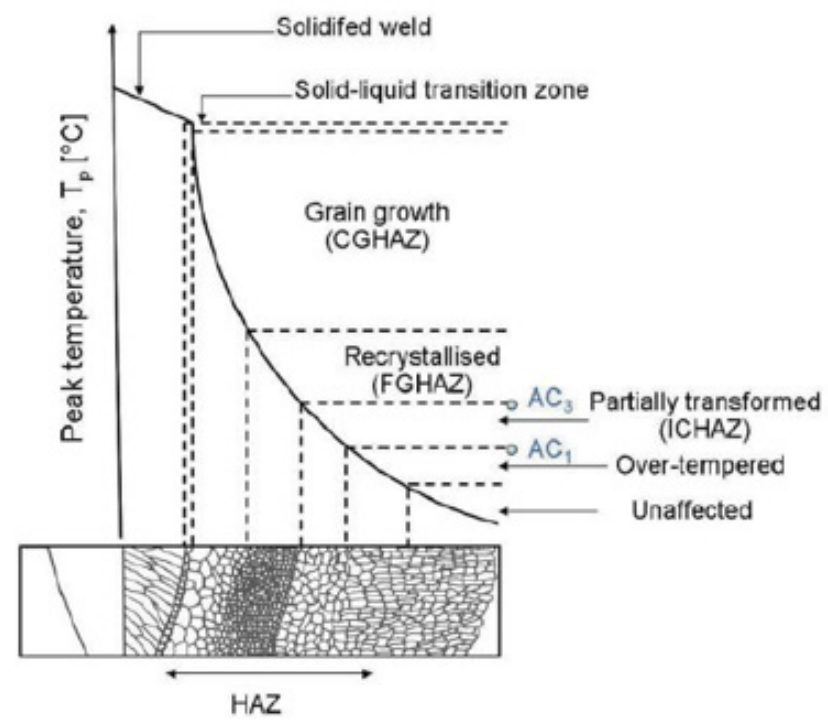

Figure 2: Schematic illustration of the heat-affected zone [4].

- $\quad$ Coarse grain zone

- $\quad$ The normalized zone

- The partially transformed zone,

- $\quad$ The annealed zone

However, according to Lippold [5], the HAZ was subdivided into two regions, the partially melted zone (PMZ) and the "true" heataffected zone (T-HAZ). The PMZ exists in all fusion welds made in alloys since a transition from $100 \%$ liquid to $100 \%$ solid must occur across the fusion boundary. According to Lippold [5], there are many possible metallurgical reactions in the HAZ: recrystallization, grain growth, phase transformations such as precipitation, and residual stress and stress relaxation.

\section{Mechanical properties of HAZ}

The mechanical properties and microstructures of the HAZ have its origin in the thermal heat treatment during welding and depend on the characteristics of the joint (position in the joint, thickness of the joint) and the heat input and the prior-heat treatment before welding (if it is applied) [6].

\section{Controlling of HAZ}

It has been concluded that by improving the microstructure of the HAZ, the properties of the welded joint can be improved [7]. The changes of microstructures in the HAZ depend on the level of thermal exposure and are varying with distance from the weld metal zone. High heat input increases the size of the HAZ which induces a low impact strength [8]. As reported by Gu et al. [9], the 
degradation in strength and toughness of welded joint, is generally happens in HAZ.

As many authors, Parmar and Dube [10] considered HAZ as the most complicated region. It is important to control its effects. HAZ is the most critical region in the welded joint as it affects the microstructure and grain size of weld bead. The main factors for improving welded joint quality are: welding process, material selection, and welding parameters. Concerning the welding parameters, they found that in order to study the heat-affected zone in welded carbon steel, following parameters were considered: welding current, welding speed, and arc voltage. These parameters can influence the Heat input and heat flow.

According to Lippold [5], heat input and heat flow conditions have an effect on the dimensions and nature of the HAZ. These dimensions are controlled by the temperature gradient from the fusion boundary into the surrounding base metal and the nature of the metallurgical reactions that occur over that temperature range. The size of HAZ has been studied by Śloderbach and Pająk [3]. They established an expression for determining the value of $\mathrm{x}$ of HAZ for a given time $t$ and knowing diffusivity coefficient $\kappa$ of given material:

$$
[\mathrm{x} /(2 \sqrt{\kappa \mathrm{t}})] \approx 0.61
$$

From this mathematic expression, the size of the HAZ $\mathrm{x}$ can be controlled by the time $t$ during the welding. The $\mathrm{x}$ can be reduced by reducing the welding time.

\section{Methods of Investigation of HAZ}

It has been found that the study of the HAZ of real welded joints is not easy because of the narrowness of the HAZ [11]. Welding simulation is the appropriate technique to determine the different sub-zones in HAZ. This allows the prediction of the microstructure and the properties of these sub-zones [9]. Consequently, thermal cycle simulation in which the HAZ can be geometrically extended is the appropriate method in order to determine the different microstructures, which can be developed in real welded joints $[12,13]$.

Hamza et al. [14] simulated HAZ of the welded stainless steel $304 \mathrm{~L}$ by the thermal cycle simulation technique and compared it to the HAZ obtained from the real welded joint. They found that the simulated HAZ by the thermal cycle simulation technique has given more information. The HAZ is heterogeneous structure, because it is formed with different subzones. Raouache et al. [15], investigated the HAZ of welded 2014 aluminum alloy by the thermal cycle simulation of the base metal. They found that the HAZ is also a heterogeneous zone, because it is composed with different subzones and each subzone has a specific microstructure.

\section{Conclusion}

From the above literature, followings points can be summarized:

- The HAZ is the critical zone in welded joint, for this reason it is necessary to control its effects.

- $\quad$ The HAZ is a heterogeneous zone and it can be divided into different subzones

- $\quad$ There are many possible metallurgical reactions in the HAZ

- The mechanical properties and microstructures of the HAZ depend on the heat input during welding

- $\quad$ Main factors for improving weld joint quality such as the welding process, the material selection, and the welding parameters.

- Welding simulation is a suitable technique for the investigation of the HAZ and to determine the various HAZ subzones.

\section{Acknowledgement}

None.

\section{Conflict of Interest}

No conflict of interest.

\section{References}

1. Smallbone C (2019) IIWAP2019: The 8th Asia-Pacific IIW International Congress, March 20-22, QSNCC, Bangkok, Thailand.

2. Back M (2015) Welding of dissimilar metals in different welding positions, Examensarbette I Material Design 300 HP, Avancerad Niva Stockholm, Sverige.

3. Śloderbach Z, Pająk J (2015) Determination of ranges of components of heat affected zone including changes of structure. Archive of Metallurgy and Materials 60(4): 2607-2612.

4. Krishnasamy RK (2012) A computational approach to thermomechanical fatigue life predictions of dissimilarly welded superheater tubes, Grin Verlag, Germany.

5. Lippold JC (2014 ) Welding Metallurgy and Weldability. John Wiley \& Sons, Inc, Hoboken, New Jersey.

6. Stemne D, Narstrom T, Hrnjes B (2010) Welding Handbook: A guide to better welding of Hardox and Weldox. SSAB, pp. 132, Stockholm.

7. Digheche K, Boumerzoug Z , Diafi M, Saadi K (2017) Influence of heat treatments on the microstructure of welded of APX70 pipeline steel. Acta metallurgica Slovaca 23(1): 72-78.

8. Gunaraj V, Murugan N (2002) Prediction of Heat-Affected Zone Characteristics in Submerged Arc Welding of Structural Steel Pipes. Welding research, 94-98.

9. Guo YH, Lin L, Zhang D, Liu L, Lei MK (2018) Microstructure and Mechanical Properties of Heat-Affected Zone of Repeated Welding AISI 304N Austenitic Stainless Steel by Gleeble Simulator. Metals 8(10): 1-14.

10. Parmar A, Dubey A (2017) Study of heat affected zone for SMAW process for low carbon steel specimen with controlled parameters, IJMTER.

11. Dunder M, Vuherer T , Kladaric I (2010) Weldability Investigation of TStE 420 After Weld Thermal Cycle Simulation. Strojarstvo 52(2): 97104.

12. Glover NE , Davis CL (1996) Thermal cycle simulation of a Ni-base superalloy. Scripta Materialia 34(5) 675-684.

13. Dunder M, Samardzic I, Klaric S (2007) Influence of cooling time $\delta \mathrm{t} 8 / 5$ on welded joint properties of the thermal cycle simulated TStE 420 specimens. Tehnicki Vjesnik 14(1-2): 47-57. 
14. Hamza S, Boumerzoug Z, Raouache E, Delaunois F (2019) Simulated heat affected zone in 204L steel. Acta Metallurgica Slovaca 25(3): 142-149.
15. Raouache E, Boumerzoug Z, Delaunois F, Khalfallah F (2020) Investigation by Thermal Cycle Simulation of Heat Affected Zone in Welded AA2014 Aluminum Alloy. Res Dev Material Sci 13(3): 1407-1411. 